\title{
Introducing Legal Clinics in Olomouc, Czech Republic
}

\section{Vendula Bryxová - Maxim Tomoszek - Veronika Vlčková Law Faculty of Palacky University, Olomouc, Czech Republic}

\section{The Czech context}

In the Czech Republic, clinical legal education is not very developed. It does not fit into the traditional view of legal education, which itself is based mainly on an Austrian and German legal tradition which emphasizes legal positivism, legal history and a lecture style of lessons.

The university environment in the Czech Republic is very conservative. Open minded teachers (mostly young assistants) have very little space for their own creativity during the lessons. Most of the Czech law teachers do not have any training in teaching methodology. Moreover the general attitude is that there is no special need for practical courses because "the students will receive their practical training once they are in practice after finishing the law school".

These attitudes result in very sceptical approach to the methodology of teaching, if we can speak about any methodology at all. To put it simply, the content of the lecture is seen as more important than the way the content is taught.

The knowledge-based approach of the Czech legal education is also very closely related to the lack of evaluation, assessment and reflection of the teaching process. Czech law teachers do not use these methods for several reasons. First, because they do not want to be evaluated; secondly they take evaluation very personally; thirdly they do not know how to make use of such evaluation; and fourthly they think the students cannot properly assess the quality of teaching. Even though students would be prepared to evaluate the teaching, most teachers would not know how to be evaluated. Equally the students have no motivation to evaluate the teaching process because they feel it is not going to have any effect.

The lack of student motivation affects education as a whole. There is a need to raise the general level of student motivation so that students are able to participate actively in their education. The general habits of the students are that they study only right before their exams, which means the learned information stays in their memory only for short time and in the long run, they can remember only a small fraction of it.

In relation to clinic specifically there are particular fears that the provision of free legal aid will mean that clinics will steal work from practising advocates - including the university lecturers who work as advocates. Such staff is therefore not greatly interested in helping to establish the clinics or taking part in them.

Finally, it should be noted that faculties are usually managed by old conservative professors, who are not 
very fond of incorporating the practical courses into the law faculty's curriculum. There may be a degree of fear of the unknown, and in any event they are convinced their teaching methods are the best (they have used them with "good" results for such a long time). Most of the teachers still teach according to the old methods and in accordance with the motto "teachers are those who know, i.e. demigods, the students on the other hand know nothing". This causes a huge gap between teachers and students and it makes communication very hard.

\section{The Palacky University context:}

The Law Faculty of Palacky University in Olomouc is in some respects special even within the Czech environment. It is quite a young institution (being established in 1991), which means that the staff mostly consists of young teachers, enthusiastic and willing to do something new, to change the system of education as a whole. The management staff is also quite young and the institutional obstacles are therefore not as impenetrable as at the other faculties.

Even though we were able to incorporate some practical courses, problems have not disappeared. We have found out how difficult it is to manage the financing of the clinic, and establish a staff group with the necessary backgrounds. Teachers within the Law Faculty of Palacky University in Olomouc are likely to carry a substantial teaching load of lessons in doctrinal law. They are unlikely to have any training in clinical teaching methodologies. And the majority of them will not be practitioners since practitioners prioritize their own practice to teaching because teaching is both time-consuming and unprofitable when compared to the rewards of practice.

\section{Legal clinics at Palacky University}

Even though the Law Faculty of Palacky University in Olomouc, Czech Republic, was probably the first law faculty in Central Europe to start a legal clinic, ${ }^{1}$ in following years it stagnated both in number of students and in quality of education, especially due to the lack of finance and the lack of people who were willing to be involved.

The clinic then benefited from a joint project of European Social Fund and Ministry of Education of the Czech Republic ${ }^{2}$ which granted the Olomouc Law Faculty funding for period of July 2006 to June 2008. There are currently five legal clinics embedded in the curricula of the Law Faculty of the Palacky University in Olomouc - Students' Legal Advising Office, Administrative Law Clinic, Refugee Law Clinic, Human Rights Clinic and Clinic of Electronic Communications Law.

In total, there are more than 80 students taking part in clinical subjects, while eleven members of faculty and five experts from different NGOs are teaching and supervising in these clinics. The Students' Legal Advising Office is a live-client clinic, while the other clinics function on a mixed basis, i.e. combining various clinical methods (internship, externship, live-client work, simulation and so on). The Centre for Clinical Legal Education, which provides organizational and administrative support for functioning of the clinics, was established as an organisational unit of the faculty.

Legal clinics in Olomouc are not based solely on common law models of clinical legal education. In 2006 we started a very successful cooperation with the Polish Foundation of Legal Clinics. The co-operation with the Polish legal clinics was very helpful especially during the preparation of the clinical programs.

1 With the kind help of Professor Stefan H. Krieger of Hofstra University School of Law in 1996

2 "Development of Practical Forms of Education at Law Faculty of Palacky University in Olomouc" 
In general terms, for the majority of general practical questions concerning the organization and methodology we drew inspiration from the US and the UK legal clinics, while the narrower practical questions of organization were taken from Poland, which enabled us to take advantage of the same legal system, similar cultural and social environment. ${ }^{3}$

\section{Our experiences in implementing the clinics}

This section focuses on our experience of introducing clinical legal education in the Czech Republic, focusing on problems we encountered or anticipated, what in our opinion their sources were and how we have resolved or avoided them.

Given that the idea of clinical legal education originates in and is very tightly connected with common law system, in the stage of preparing and designing the clinical subjects for Olomouc Law Faculty, which operates within our Czech civil law environment, we wondered whether there would be some problems deriving from differences between the common law systems and civil law system and how we would overcome them if they did arise.

One of the problems we anticipated arose in relation to the status of case law. Case law presents an important difference between the civil and common law systems since in civil law systems the search for judicial decisions is not as significant at the case analysis stage as it is in common law systems which are based on judge-made law (precedents). Throughout their studies, our students' work is focused mainly on abstract law and codes, whereas in common law systems students work extensively with case-law, which is without any doubt much more practical form of education since it tends to teach the students how the law is applied in a particular case.

We were therefore concerned as to how the Czech students would make the jump from a mostly theoretical education to the case-oriented approach of clinical education. However our experience shows that most students involved in the clinical legal education were able to start working on the cases of the clients coming to the clinic almost at once, although some of them required a short period (two weeks to one month) of more intensive cooperation with their supervisor to feel comfortable when working on the case. We were also pleased to find out, that students were quite happy to work with case law (such as European Court of Human Rights case law in a human rights clinic), since for them it was more or less an untouched area and therefore interesting and motivating, resulting in very good student outcomes.

\section{Other issues in the clinic}

After analyzing this issue and finding out that it was not as problematic as we thought it might be we started to analyze other problems we were experiencing. We realized that the rest of problems were either not related to the difference between common law and civil law at all or to a far greater extent arose from other sources, such as cultural and social diversity and differences between systems of education.

The liability issue: This feature has been of the utmost importance to us. It is clear that the students, who are helping the clients as a part of their education, should not be held liable for damage clients can suffer as a result of students' activity. However it is not easy to avoid such liability. Even though most live-client clinics require their clients to sign a statement that they are aware their case is going to be handled by the students in the legal clinic as a part of the students' legal education, and acknowledge that the students

3 In particular we should give credit to the book The Legal Clinics. The Idea, Organization, Methodology. [http://www.fupp.org.pl/down/legal_clinic.pdf], which helped us a lot. 
will not be liable for any damage caused as a consequence of their help, the liability of the university still remains. This can to some extent be addressed through the provision of insurance cover. However, the amount of damages that the insurance covers may not always be adequate. We have therefore needed to take other measures such as introducing criteria for refusing cases, where the potential liability would be too great.

The practitioner/academic divide: Another problem is that the most of the teachers at the Law Faculty of Palacky University in Olomouc are not practitioners or advocates, which impacts on skills development and legal ethics. As we have suggested, experienced specialists who could share their practical experience with students are not interested in teaching at law faculty - they are too busy or the teaching is not profitable enough for them to do it. On the other hand teachers within the faculty lack practical experience, so that it can be hard for them to pass on the knowledge, and students often do not have enough confidence in them. Even where practitioners do contribute to the teaching, in our view the experienced lawyers usually lack experience of interactive teaching methods.

Currently, in order to resolve this, we apply the following model: the education is mainly the responsibility of law faculty teachers, who focus on skills development, while at the same time we try to involve experienced practicing lawyers in the clinic as much as possible in order to transfer practical experience to students. It has also proven very helpful to cooperate with various NGOs. The lawyers working in NGOs have very valuable practical experience and at the same time they are able to teach very effectively using advanced teaching methods such as simulation. Additionally they also tend to bring a positive attitude to pro bono work.

The organization of legal clinics: Clinical administration and organisation gives rise to a number of specific issues for our clinics.

Case selection: In the first place there are issues around case selection. In general the legal clinics do not accept all potential cases; quite often there are precise selection criteria for accepting the case, for example, the lack of finances on the part of the client. In the Czech Republic, there are many people in need of free legal aid, which thus creates a good environment for live-client clinics. In order to control the number of clients we cooperate with our NGO partners. Those clients whose cases are too complicated for our students are handed over to the NGOs. Equally where the NGOs are faced with too many clients, they may refer clients to our clinics.

The clinic does not take on any form of criminal case, largely because these are perceived as particularly risk-intensive for the clinic. Additionally we do not take on cases that arise in relation to issues between advocates and their clients, or cases which are likely to be overly complicated - such as property restitutions. Nor do we accept clients who are already represented by an advocate or clients who can apparently afford one.

Pre-requisite knowledge: We also face the difficulty of ensuring that students have sufficient knowledge to be able to help clients or otherwise participate in the clinic. When deciding the syllabus of the Students' Legal Advising Office, which is a live-client clinic, we could afford to design it to be almost completely practical, because the vast majority of clients' cases solved by the students were relatively simple cases in areas of law that had been taught very extensively during previous modules. There are, however, areas of law, such as refugee law that are not covered in any prior non-clinical studies, which means the students enter the clinic without having any knowledge of the relevant substantive law. It has therefore been necessary to design the Refugee Law Clinic so as to include a theoretical component in order to ensure that students have enough knowledge to successfully go through the practical part of the clinic. 
Representation at court: Another important issue for us was whether the students should be able to represent clients in court. There are some clinical projects in other jurisdictions where the students are eligible to represent clients before the court. This makes the clinical courses more attractive and allows the students to gain a more profound understanding of judicial proceedings.

In respect to this, the Czech law provides for non-professional occasional representation before the court (in some aspects similar to the concept of the amicus curiae). This might apply to clinical students and would thus allow them to participate in any court proceedings. However we have decided that students will not be permitted to do so. There are two reasons for this: the first is to avoid possible conflict with local advocates; the second is the issue of liability, since we are still not sure whether the insurance would cover activities of students within judicial proceedings. However this is something that we are keeping under review for future years.

\section{Clinical issues and the wider educational context}

We believe that the rest of the problems we mention here have a very close connection with the organization of legal education and, moreover, with organization of education as a whole.

As has already been mentioned above, in the Czech Republic there are in general no special courses on any type of skills at any level of education and there is no tradition of teaching them. The older generation of lawyers were not themselves taught legal skills, and would find it difficult themselves to teach students legal skills. This corresponds with the stereotype of how ordinary people perceive a lawyer - someone with knowledge, rather than skills. Thus even university students have very little sense of the legal skills which a legal practitioner should have. In consequence they have no real expectations concerning the extent of skills training that they need or the need for the improvement of those skills that they already possess.

In general the Czech system of education is focused on theory and the transmission of specific theoretical findings. This contrasts with, for example, the UK or the U.S. where, in our opinion, much more emphasis is placed on teaching through student activity, on communication and the application of knowledge - as well as on skills development. In our view skills build a bridge between theory and practice, and we therefore feel that we need to maximize the teaching of legal skills in any form within our law faculty's curriculum.

We can provide a good example of the way in which knowledge is prioritized within our system. At the Law Faculty of Palacky University in Olomouc, due to the lack of skills training during the legal education we decided to conduct a workshop on legal skills for students involved in legal clinics. One part of the workshop consisted in simulated client interview. The students were taught by advocates, who also had some teaching experience. However, when it came to evaluation, the lecturers focused on knowledge the students exhibited, but did not pay any attention to use of skills during the interview.

Student and staff expectations in relation to legal education - and clinical education - cannot be disregarded, as the influence of teachers' expectations concerning the work of students and their study results is also obvious. These expectations (from both students and teachers) focus on the achievement of defined theoretical conclusions, not on skills development. A good example of this attitude is shown in the lessons conducted by experienced specialists (such as advocates and public officials), who would often hold a tedious lecture (and thus completely avoid addressing their own practical experience) instead of using simulation or another interactive method, which could also have developed students' skills.

However this is not simply an issue of the approach adopted by the teaching staff. Students themselves do not expect teachers to use other than didactical methods of education. Thus at the workshop on legal 
skills which we mention above, a professional psychologist started his lesson by asking the students about their interests and expectations concerning the lesson (and thus concluding an educational contract with them) with the intention that the students gained the sense of being the ones who decided the content of the lesson. However after the lesson the students evaluated the psychologist as "not having the lesson sufficiently prepared, because at the beginning he asked students, what they would like to do"!

Our solution to this problem is to insist on the use of interactive teaching methods by all teachers and sometimes even "forcing" students to play an active part during the lessons. However this is not always possible, due to the great number of teachers who have never experienced such methods during their studies. Moreover, the students are used to passive forms of teaching with the teachers presenting everything needed without any effort being needed by the students.

In addition to these issues with expectations of teaching styles and methodologies, we also face difficulties in relation to teaching certain subject areas - in particular the teaching of legal ethics. This is a subject that is traditionally taught in western countries. However, during the communist era in the Czech Republic the traditional conception of legal ethics was violated and the development of the subject stopped. Ethics, as a subject for teaching, was neglected; it has not been taught at schools. In our view the level of morality diminished during this time and this was reflected in the law as well. Now there is a new opportunity to start the teaching of legal ethics either as a new subject in our curriculum or as a part of existing subjects. The impact of the lack of legal ethics teaching as a part of the legal education curriculum can arguably be seen in ethical frailty of some advocates in practice, perhaps arising from the fact that students are not taught about how to develop an appropriate relationship between an advocate and a client.

Another wider curriculum problem which affects the development of clinical programmes and skills development is assessment. We (and here we can speak for our whole clinical team) know how to evaluate knowledge. But we also know that within the clinical education the focus of the assessment may be on areas such as legal skills, particularly since possession of sufficient knowledge is a prerequisite for entering the clinics. However, since students spend considerably less time in clinics compared to the UK or the U.S. legal clinics, the consequence is that the contact between students and teachers is not intensive enough to allow for the assessment to be based solely on one's own observations of the students. That is why there is a pressing need for some form of externally reviewable assessment.

With this in mind we required clinical students to produce a reflective journal. This worked well but we came up against the problem of insufficient earlier skills development: students do not know how to reflect and some of them do not want to reflect at all (being afraid of sharing their perceptions, and feelings, and trying to protect their privacy). Most students do not even understand the meaning of the reflection as an invaluable part of learning process. Lack of the reflective skills came out very clearly during the evaluation of reflective journals after the first semester of the legal clinics. The reflective journals were almost completely descriptive and thus tended to reach no more than the first level of reflection at best. Having said this, however, we note that in our discussions concerning reflection with our colleagues from the UK, they have made clear that often they experience similar problems with student reflection, and that the solution is not an easy one.

The issue around reflection connects with another phenomenon that exists in the Czech Republic - the aversion to, and the fear of, sharing one's own opinion. This hunger to merge with the crowd and not to differ is the inheritance from the communist regime. There was only one accepted opinion and nobody was ever asked to present his own opinion. But the problem is also with the traditional teaching methods - with the reliance on lectures and seminars. Seminars, which are intended to practice and discuss the problems 
covered by the lecture, often end up looking very similar to lectures; they have the same expository character. Most of the times the teachers use the seminars to catch up in what have not been covered at the lecture and there is no space for discussion, solving problems. When occasionally there is some element of discussion of practice in seminars, the teachers still do not use the practical and interactive methods of teaching.

In our opinion this also shows that there is a need for practical forms of education focusing on legal skills development in civil law systems. It seems to us that while in common law systems students acquire lawyering skills during their studies as a "by-product" of the learning style, this is not true in civil law systems. As against this, however, one should point out that in the Czech Republic there is no pressure on law faculties to include legal skills training in their curricula, because the most legal professions like judge, advocate or prosecutor require a three-year period of practice and exam. It is generally felt that graduates will have enough time during this period to develop legal skills in practice.

\section{Conclusions}

In our introduction of legal clinics into the curriculum of the Law Faculty of Palacky University, we found the experience from both civil law clinical models and common law clinical models extremely helpful. The differences that arose in introducing clinic into the Czech Republic were not only connected with law but also with social and cultural differences as well. Although the sources of our clinical inspiration were in different jurisdictions, we think that it is essential not to just mechanically transpose the experience from one system to another, but rather to identify the potential problem areas features in order to avoid them. Interestingly although we were worried about the impact of the differences between common law and civil law, we did not find any major conflicts that would exclude transferring experience from one system to another.

So far we have identified only one problem arising from the differences between two legal systems and that is the use of case law during work on specific cases. In the Czech Republic, because of the civil law system, the use of the case law is not that important in case preparation, so that the consequences of insufficient case law analysis are not that serious. On the other hand through using the case law in the clinics students start to focus on a more case-oriented approach to Law.

The other problems we have faced are connected with the particular context of the Czech educational system, and the approaches and general attitudes to legal education from both teachers and students. In our opinion the most important common problem of legal education (and clinical legal education in particular) is the development of transferable legal skills. In some countries, like our own, this may be very acute problem, because the lower levels of education are very knowledge-oriented and the skills are not being taught. The consequence is that even where teachers want to start teaching skills, they have to do so in a knowledge-oriented environment and therefore with a lack of support and understanding, and with little experience of skills teaching methodologies. In this regard it is enormously useful to be able to draw on teaching experiences from other jurisdictions with a tradition of skills teaching.

In relation to the legal clinics at the Law Faculty of Palacky University in Olomouc, the key problems are mainly those concerning the liability for damages, case management (including case selection criteria) and the lack of experienced supervisors. There is also the problem of the lack of any prior exposure to legal ethics teaching for the students. When facing all of these problems we had to find some functional solutions. We are aware that most of the solutions we have found are temporary and that we might find better ones as we get more experienced in running the legal clinics. However we also note that when we spoke to 
colleagues from other jurisdictions about many of these issues, they tended to confirm that they were facing many of the same problems - the quality of students' reflection in reflective journals, lack of teachers with practical experience, problems in communication with students and so on. This supports the idea that there are fundamental similarities in clinical education regardless of legal systems. Social and cultural differences and especially the difference between systems of education can sometimes be very challenging but in our opinion far from being irresolvable. In the era of globalization it is clear that these differences are vanishing. 